\title{
REFORMULASI SISTEM PERENCANAAN PEMBANGUNAN NASIONAL MODEL GBHN SEBAGAI PELAKSANAAN ASAS KEDAULATAN RAKYAT DALAM RANGKA PERUBAHAN KE-V UUD 1945
}

\author{
Eric Stenly Holle \\ Fakultas Hukum Unpatti Ambon \\ Dosen Hukum Hukum Tata Negara
}

\begin{abstract}
ABSTRAK
GBHN atau Garis Besar Haluan Negara, adalah bentuk catatan rencana pembangunan negara Indonesia. Dan merupakan keinginan bersama rakyat Indonesia secara menyeluruh (garis besar) yang dibuat oleh MPR sebagai miniatur rakyat di pemerintahan. Didalam GBHN juga tertera aturan-aturan jalannya pembangunan negara yang harus berlandaskan kepada UUD 1945 sebagai tempat tertulisnya tujuan atau cita-cita negara Indonesia. Permasalahan mengenai stagnasi pembangunan yang seringkali dirasakan dewasa ini membuat romantisme kepada GBHN kembali disemarakan. GBHN sangat penting agar arah dan program maupun kebijakan pembangunan nasional tak berubah-ubah berdasarkan rezim yang sedang berkuasa. Jika GBHN dihidupkan kembali maka harus mengamandemen UUD 1945 dan beberapa undangundang terlebih dahulu, karena setelah zaman reformasi, ada Undang-undang yang diamandemen sehingga GBHN tidak diperlukan lagi. Maka dari itu, jika ingin menghidupkan kembali GBHN, MPR harus mengamandemen undang - undang yang tidak sesuai dengan GBHN. Konsekuensinya adalah pada mekanisme pemilihan presiden secara langsung karena bisa saja MPR kembali menjadi lembaga tertinggi negara dan mempunyai kewajiban untuk memilih kembali presiden disamping membuat dan menetapkan GBHN.
\end{abstract}

Kata Kunci : Reformulasi, GBHN, UUD 1945

\begin{abstract}
Guidelines or Guidelines of State Policy, is the record of development plans form the country of Indonesia. And is the common desire of the Indonesian people as a whole (outline) made by the Assembly as a miniature of the people in government. In the guidelines also contained rules of the course of development of the country should be based on the 1945 Constitution as a written goals or ideals of the Indonesian state. Issues regarding the stagnation of development is often perceived today make romance to the guidelines back obfuscated. The Guidelines are very important for the direction and national development programs and policies do not change by the incumbent regime. If the guidelines revived it must amend the 1945 Constitution and several laws in advance, because after the reform era, there Act was amended so that the guidelines are no longer needed. Therefore, if you want to relive the Guidelines, the Assembly should amend laws - laws that are in accordance with the Guidelines. The consequence is that the mechanism of direct presidential elections because it could have the Assembly back into the highest state institution and has an obligation to reelect the president in addition to making and establish guidelines.
\end{abstract}

Keywords: Reformulation, Guidelines, UUD 1945 


\section{A. PENDAHULUAN}

Dalam sebuah negara demokrasi kekuasaan tertinggi berada ditangan rakyat dan karenanya rakyatlah yang berdaulat. Sebelum UUD 1945 kedaulatan rakyat itu dipegang dan dilaksanakan sepenuhnya oleh MPR. Namun setelah UUD 1945 terjadi perubahan yang fundamental (mendasar) dalam sistem ketatanegaraan Indonesia, terutama dengan dianutnya sistem demokrasi langsung di Indonesia dan salah satu konsekuensinya kedaulatan rakyat tidak lagi dipegang oleh MPR. Ada banyak faktor, mengapa pilihan jatuh pada demokrasi lansung, dan salah faktor yang dominan yang mendorong pilihan pada demokrasi lansung tersebut adalah dominan adalah didorong oleh kondisi politik dan demokrasi yang berlangsung pada Era Orde Baru dengan segala dinamikanya. Dasar hukum kewenangan MPR termaktub di dalam Pasal 3 Amandemen UUD 1945 yakni :1). MPR berwenang mengubah dan menetapkan UUD 1945; 2). MPR melantik Presiden dan/atau wakil Presiden. 3). MPR hanya dapat memberhentikan Presiden dan/atau wakil Presiden dalam masa jabatannya menurut UUD 1945.

Pasca Amandemen UUD 1945 terdapat berbagai perubahan terkait dengan sistem ketatanegaraan. Perubahan tersebut antara lain :1). Perubahan terhadap sistem demokrasi perwakilan/tidak langsung ke demokrasi secara langsung. 2). Presiden dan Wakil Presiden tidak lagi dipilih oleh MPR tetapi dipilih langsung oleh rakyat dalam satu paket.3). MPR bukan lagi sebagai lembaga tertinggi negara, tetapi sudah setara dengan lembaga negara lain. 4). MPR tidak lagi menyusun dan menetapkan GBHN. 5). Presiden tidak lagi bertanggungjawab kepada MPR.

Salah satu hasil amandemen yang krusial terhadap UUD 1945 adalah hilangnya GBHNsebagai pedoman atau haluan negara dalam pelaksanaan pembangunan nasional. GBHN inihilang seiring dengan berubahnya tugas lembaga MPR sebagai konsekuensi dari berubahnyaposisi kelembagaannya dari lembaga tertinggi negara menjadi lembaga tingi negara sejajardengan lembaga tinggi negara lainnya, yaitu presiden, DPR, DPD, MA, BPK, dan MK.Implikasi lebih lanjut pemangkasan 
ISSN 2528-360X e-ISSN 2621-6159

kewenangan MPR di atas, program pembangunan yang pada awalnya tertuang dalam GBHN tidak memperoleh tempat.

Sebagai terobosan hukum, diundangkanlah Undang-Undang Nomor 25 Tahun 2004 tentang Sistem Perencanaan Pembangunan Nasional. Sebagai tindak lanjut dari UndangUndang SPPN, diundangkanlah UndangUndang Nomor 17 Tahun 2007 tentang Rencana Pembangunan Jangka Panjang Nasional Tahun 2005-2025.Moeljarto Tjokrowinoto memberikan makna perencanaan pembangunan sebagai konsep yang menyangkut dua aspek yaitu pertama sebagai suatu proses perumusan rencana pembangunan, dan kedua sebagai substansi rencana pembangunan itu sendiri. (Moeljarto Tjokrowinoto, 1993 : Hlm. 92)

Sementara itu Riyadi \& Deddy Supriady B mengartikan perencanaan pembangunan sebagai suatu proses perumusan alternatif-alternatif atau keputusan-keputusan yang didasarkan pada data-data dan fakta-fakta yang akan digunakan sebagai bahan untuk melaksanakan suatu rangkaian kegiatan/aktivitas kemasyarakatan, baik yang bersifat fisik (material) maupun nonfisik (mental spiritual),
Volume 1 No. 1 Desember 2016

dalam rangka mencapai tujuan yang lebih baik. (Riyadi \& Supriadi B, 2005 : Hlm. 7)

\section{$\underline{\text { Sistem Perencanaan }}$}

Pembangunan Nasional adalah satu kesatuan tata cara perencanaan pembangunan untuk menghasilkan rencana-rencana pembangunan dalam jangka panjang, jangka menengah, dan tahunan yang dilaksanakan oleh unsur penyelenggara negara dan masyarakat di tingkat Pusat dan Daerah.Dari sisi jangka waktu, perencanaan pembangunan jangka panjang nasional (RPJPN) mempunyai kurun waktu 20 tahun, perencanaan pembangunan jangka menengah (RPJM), dengan kurun waktu 5 tahun, dan rencana kerja pemerintah (RKP) dengan kurun waktu 1 (satu) tahun.

Hilangnya GBHN berarti hilangnya sarana pemandu pelaksanaan pembangunan nasional. Dengan GBHN pembangunan dapat dilaksanakan secara terencana, terkendali dan terevaluasi. Karena posisinya yang krusial sebagai pemandu pelaksanaan pembangunan maka GBHN yang hilang harus ada penggantinya. Karena itulah di era reformasi ini muncul RPJPN yang oleh rezim pembuatnya dimaksudkan sebagai pengganti GBHN. Belakangan 
RPJPN mendapat banyak tangapan kritis karena dianggap tidak representatif sebagai pengganti GBHN, alias tidak kredibel untuk disebut sebagai panduan dalam pelaksanaan pembangunan. Fenomena pelaksanaan pembangunan antara pusat dan daerah dan antar daerah yang saling tidak sinkron karena jalan sendiri-sendiri yang terjadi saat ini ditengarai sebagai bukti nyata inkredibiltas tersebut. Untuk dapat segera kembali ke rel yang benar dalam pelaksanaan pembangunan maka konsep perencanaan pembangunan harus segera dibenahi.

Berdasarkan kewenangan pada Pasal 3 Amandemen UUD 1945 maka, MPR tidak lagi memiliki kewenangan untuk membuat GBHN. GBHN adalah haluan negara tentang penyelenggaraan negara dalam garis-garis besar sebagai pernyataan kehendak rakyat secara menyeluruh dan terpadu yang ditetapkan oleh MPR untuk mewujudkan kesejahteraan rakyat yang berkeadilan. Untuk itulah muncul wacana reformulasi terhadap GBHN mulai digulirkan kembali oleh MPR dalam menentukan arah pembangunan nasional. Dalam rangka amandemen keV terhadap UUD 1945 maka, penting untuk membahas wacana dimasukan kembali GBHN dalam kewenangan MPR.

\section{B. PEMBAHASAN}

1. Pentingnya GBHN Dalam Menentukan Arah Pembangunan Nasional di Era Reformasi.

GBHN merupakan pernyataan keinginan rakyat yang menjadi acuan utama atas segala kiprah penyelenggara negara dalam mewujudkan cita-cita bangsa bernegara, yang secara explisit tesurat didalam pembukaan UUD 1945. Upaya mewujudkan cita-cita bangsa secara sederhana diartikan sebagai upaya pembangunan bangsa. Karena pembangunan itu sendiri dapat diartikan sebagai peningkatan kualitas dan derajat kehidupan seutuhnya dari seluruh rakyat Indonesia. Oleh karenanya bentuk operasional dari GBHN ini selama beberapa dekade diwujudkan dalam bentuk Rencana Pembangunan Nasional.

Pada periode 1968-1998, landasan bagi perencanaan pembangunan nasional adalah ketetapan MPR dalam bentuk GBHN. GBHN menjadi landasan hukum perencanaan pembangunan bagi presiden untuk menjabarkannya dalam 
ISSN 2528-360X e-ISSN 2621-6159

bentuk Rencana Pembangunan Lima Tahunan (Repelita). Proses penyusunan GBHN bersifat sentralistik dan TopDown. Lembaga pembuat perencanaan didominasi oleh pemerintah pusat dan bersifat ekslusif. Pemerintah Daerah dan masyarakat sebagai subjek utama output perencanaan kurang dilibatkan secara aktif sehingga mematikan inovasi dan kreatifitas daerah dalam memajukan dan mensejahterakan masyarakatnya.

Pada masa orde baru pun sebenarnya telah dikenal istilah perencanaan partisipatif melalui Pedoman Penyusunan Perencanaan dan Pengendalian Daerah (P5D) yang dikelola oleh Departemen Dalam Negeri (Permendagri No 9 Tahun 1982), dengan ketentuan teknis yang sangat rinci. Falsafahnya adalah menjaring aspirasi masyarakat, mulai dari tingkat desa, kecamatan, untuk dibawa ke tingkat pusat melalui serangkaian forum-forum pertemuan dan konsultasi. Namun dalam kenyataannya sangat sedikit usulan-usulan pembangunan dari tingkat desa yang dimasukkan dalam agenda pembangunan Provinsi dan Nasional. (Sjaifudian H, 2000 : Hlm.
Volume 1 No. 1 Desember 2016

Meskipun bagi beberapa kalangan agak sulit mengkategorikan GBHN ini, namun selama beberapa dekade GBHN ini telah menjadi suatu dokumen yang sakti bahkan sakral, berdosa bila dilanggar. Lebih jauh lagi maksud dan tujuan dari GBHN inipun diartikan berbeda oleh satu orang dengan lainnya. Apabila ini dikategorikan sebagai visi, bukankah visi bangsa sudah tecantum didalam konstitusi?. Apabila ini kehendak rakyat, bukankah konstitusi juga merupakan wujud tertulis dari kontrak sosial untuk bangsa ini bernegara beserta tujuan bernegara?

Kontroversi dan salah kaprah akan pengertian fungsi GBHN, akhirnya disudahi dengan dirubahnya UUD 1945. Didalam perubahan yang ketiga dan keempat UUD 1945, kewenangan MPR menyusun GBHN telah dihilangkan. Berbagai konsekuensi dari perubahan UUD 1945 ini akan menjadikan kehidupan bangsa bernegara ini mengalami perubahan yang amat mendasar seperti yang telah dijelaskan penulis sebelumnya. Ketiadaan GBHN tentunya akan berpengaruh kepada sistem dan alat untuk mewujukan citacita bangsa bernegara, atau lebih sempit lagi akan merubah sistem perencanaan 
ISSN 2528-360X e-ISSN 2621-6159

pembangunan nasional. Perubahan sistem perencanaan nasional inilah yang akan dicoba dibahas didalam makalah ini.

GBHN adalah produk orde baru yang ternyata keberadaannya cukup krusial sebagai pedoman haluan dalam pelaksanaan pembangunan. Namun, aspirasi bersemangat reformasi telah menghilangkannya dari sistim pembangunan nasional. Padahal keberadaannya, belakangan disadari, tetap dibutuhkan. Kemudian dimunculkanlah RPJPN, sebagaimana tertuang dalam Undang-Undang Nomor 17 tahun 2007 tentang RPJPN. Munculnya undang-undang ini merupakan konsekuensi dari amanat Undang-Undang Nomor 25 tahun 2004 tentang Sistem Perencanaan Pembangunan Nasional. Dalam UndangUndang ini, pasal 13 ayat 1 menyatakan RPJP nasional ditetapkan dengan Undang-Undang. Kritik penulis terhadap GBHN adalah sebagai berikut :

a) GBHN masih relevan sebagai fungsi kontrol dari parlemen untuk jalannya pembangunan bangsa.

b) GBHN utamanya menyoroti konten GBHN sendiri yang
Volume 1 No. 1 Desember 2016

sifatnya normatif dan tidak spesifik.

Orde baru ditandai melalui beberapa cirinya yang khas, yaitu secara politik rezim pemerintahberperilaku sangat otoriter, sistim pemerintahan bersifat sentralistis, dan tidak ada pilpres danpilkada langsung. Penguasa eksekutif, Presiden Suharto, sedemikian kuatnya sehingga tidakada satupun kekuatan politik yang dapat mengendalikannya, justru semuanya subordinanberhadapan dengannya. Pemilu bagi sang penguasa ini hanyalah sebuah ritual limatahunanyang fungsinya terutama untuk memperbaharui legitimasi kekuasaan yang dimilikinya. Dankarena itulah semua bisa diatur olehnya. Dalam konteks inilah bisa difahami bahwawalaupun GBHN bersifat limatahunan tetapi dijamin corak dan irama kontennya pasti bisadibuat linier, karena sudah dipastikan tidak akan ada gangguan dari kompetitor manapun.

Saat ini, di era reformasi, situasi dan kondisinya sudah sedemikian berubah. Era reformasiditandai dengan terbukanya kran demokrasi dan keterbukaan berpendapat. Situasi inimembawa konsekuensi kepada berubahnya banyak mekanisme dan 
prosedur dalam tata caraberbangsa kita.

Seperti sistim pemerintahan yang berubah menjadi desentralistis, pilpres danpilkada berlangsung melalui mekanisme pilihan langsung. Kehidupan yang demokratisbegitu terasa. Kebebasan berekspressi dan berpendapat demikian terbuka. Dalam situasiseperti ini tentunya pola GBHN ala Orde baru tidaklah kompatibel untuk dipertahankan di era reformasi ini, lalu dimanakah posisi RPJPN? Setelah RPJPN ditetapkan masa berlakunya 20 tahun, 2005-2025, bisakah dijamin bahwa dokumen ini akan tetap dipertahankan sampai akhir masaberlakunya?

Terkait dengan sistim pilpres langsung yang telah menghadirkan sebuah mekanisme baru dalam proses pemilihan presiden. Dalam mekanisme baru ini jika seseorang ingin menjadi presiden maka ia harus didukung oleh mayoritas rakyat dalam pilpres. Dan kalau ingin didukung maka seseorang tersebut harus dikenal oleh massa pemilih, sejak dari siapa dirinya sampai kepada apa yang akan dilakukannya jika menjadi presiden. Karena itu seorang kandidat dituntut mampu menawarkan visi dan misi yang handal, dan agar menang maka tawarannya harus lebih baik daripada kompetitornya. Bisa dipastikan bahwa visi misi yang akan didukung rakyat pastilah visi misi yang tepat membaca situasi komtemporer kehidupan mereka, yaitu tepat dalam membaca problem yang sedang dihadapi masayarakt dan tepat pula dalam merumuskan solusi yang akan ditawarkan untuk mengatasi problem tersebut.

Lalu pertanyaannya adalah bagaimana menjamin bahwa pemenang dalam pilpres telah menawarkan visi dan misi kepada rakyat yang sama atau sejalan dengan RPJPN? Atau seandainya tidak sejalan lalu bagaimana solusinya? Sementara masa berlaku 20 tahun bagi RPJPN itu sama dengan empat kali pilpres. Mungkin sulit menjamin bahwa ke empat pemenang pilpres pada setiap periode pilpres akan konsisten taat azas terhadap materi keterbukaan di era reformasi sekarang ini mungkin lemah sehingga perlu ditinjau ulang.

Sebagai produk hukum dari MPR, GBHN tidak hanya mengikat semua lembaga Negara, namun juga lebih memberikan panduan yang komprehensif menyangkut kebijakan pembangunan nasional. Perbedaan GBHN dan RPJPN adalah dengan adanya GBHN pembangunan menjadi lebih 
terarah, tidak seperti saat ini dimana program pembangunan dibuat sesuai dengan partai pengusung presiden, sehingga kurang mengakomodir rasa keadilan rakyat.

Tetapi hadirnya Undang-

Undang RPJPN ternyata tidak serta merta membuat puas mereka yang menghendaki hadirnya sebuah dokumen pedoman perencanaan dan pelaksanaan

pembangunan sebagaimana GBHN. Kritik itu antara lain menyatakan dokumen RPJPN yang berupa Undang-Undang lemah dibandingkan GBHN yang berstatus sebagai TAP MPR. Statussebagai Undang-Undang ini memunculkan pesimisme di kalangan beberapa kritikus bahwa RPJPN akan mampu mereplace GBHN. Dengan status ini RPJPN diyakini tidak akan powerful untuk menjadi rujukan utama perencanaan pembangunan nasional. Dibanding GBHN, GBHN pada masanya bahkan begitu sakral sehingga "haram" untuk dilanggar.

Pasca reformasi saat ini, Sistim Perencanaan Pembangunan nasional melahirkan berbagai masalah diantaranya :

a) Penyusunan dan pelaksanaan RPJMN dan RPJPN dipandang lemah, karena executive perspektive.

b) Terjadi inkonsistensi dan diskontinuitas pelaksanaan RPJMN dengan RPJPN karena pergantian Presiden 5 tahun sekali.

c) RPJM Nasional tidak sinkron dengan Daerah, karena RPJM Daerah disusun menurut perspektif daerah.

Lemahnya RPJPN juga terkait dengan adanya Undang-Undang Nomor 17 tahun 2007 tentang Rencana Pembangunan Jangka Panjang (RPJP) Nasional Tahun 2005 - 2025 tidak dapat dianggap sebagai 'haluan'. Pasalnya, Undang-Undang ini lebih mencerminkan visi personal presiden yang belum tentu mengarah pada tujuan nasional.Menurut hemat penulis, RPJPN bervisi personal presiden yang bisa saja program-program kerjanya diluar ketentuan konstitusi atau tidak mempunyai faedah bagi masyarakat.

Ketika beberapa dekade sistim ini berjalan, banyak pihak menilai bahwa tanpa GBHN sebagai otoritas tertinggi yang mengarahkan pembangunan bangsa, membuat negara ini bukan lagi Negara kesatuan, tetapi Negara dengan multy government. 
Kekuasaan ada dimana-mana (Pusat dan Daerah) yang dengan mudah dapat diselewengkan untuk kepentingan diri dan kelompok dalam bentuk tindak pidana korupsi dan lain-lain.

$$
\text { RPJM yang disusun dan }
$$

dilaksanakan selama ini tidak menjawab secara komprehensif persoalan nasional yang dihadapi Indonesia, apalagi jika dikaitkan dengan konteks persaingan dan kemajuan negara-negara tetangga lainnya. Kita banyak mengalami kemunduran dalam pembangunan bangsa.

Atas dasar itu, maka MPR sendiri bahkan berbagai pihak mulai berpikir untuk menghidupkan kembali GBHN sebagai panduan untuk kepala negara (Presiden) dalam menjalankan roda pemerintahan. Presiden tidak perlu membuat program baru, karena tugas presiden hanya melaksanakan GBHN yang telah disusun. Berbagai pihak banyak yang menyesalkan penghapusan tugas MPR dalam menentukan GBHN, karena tanpa GBHN pembangunan Indonesia sulit diharapkan dapat berkesinambungan dan Indonesia tidak akan mampu menghadapi berbagai ancaman di masa depan.
GBHN sebagai aset bangsa kembali diperhitungkan dalam perannya sebagai pagar kehidupan bangsa. Hilangnya pagar kehidupan telah membuat bangsa ini dengan mudah dijamah tangan-tangan asing, dimana visi pembangunan cenderung hanyut dalam hiruk pikuk kepentingan asing sehingga kesejahteraan rakyat terabaikan. Maka itu, berbagai pihak meminta ruh dan jati diri pembangunan bangsa tetap berpijak pada aspirasi seluruh rakyat Indonesia yang dituangkan dalam GBHN.Ada beberapa perbedaan dan persamaan antara GBHN dan RPJPN

Perbedaan antaraGBHN dan RPJPN antara lain GBHN berstatus sebagai TAP MPR karena diproduk oleh MPR yang berkedudukan sebagai lembaga tertinggi negara. Secara strategis, kedudukan GBHN jauh lebih powerful dibanding RPJPN, GBHN bersifat lima tahunan. Sementara RPJPN berstatus sebagai Undang-Undang karena diproduk oleh DPR bersama Presiden dan bersifat 20 tahunan. Sedangkan persamaannya, berdasarkan aturan yang mendasari pelaksanaannya, dalam prosespenyusunan GBHN dan RPJPN keduanya telah "berkomitmen" melibatkan partisipasi masyarakat yang 
luas dan kekuatan-kekuatan politik di parlemen, GBHN di MPR dan RPJPN di DPR. Dari sisi ini sebenarnya RPJPN pun sudah cukup legitimatif untuk dijadikandasar acuan pembangunan karena secara teori telah representatif mengakomodasi semua kepentingan, tergantung kekuatan politicalwill yang mendukungnya.

Mungkin karena di bingungkan oleh begitu banyaknya masalah yang muncul di erareformasi sekarang ini bermunculanlah ide atau aspirasi untuk kembali kepada GBHN. Makna kembali dalam konteks ini, jika mencermati lontaran beberapa pihak akhir-akhir ini, merentan dari kembali kepada GBHN dalam maknanya seperti di era Orde baru sampai kepada kembali pada makna substansinya, yaitu kepada GBHN yang powerful seperti di era Orde baru terlepas dari apapun namanya "GBHN" itu. Kembali dalam maknanya yang esktrim umunya dilontarkan oleh pihak-pihak yang sejakawal keberatan terhadap dilakukannya amandemen UUD 1945. Tuntutannya adalah kembali kepada UUD 1945 pra amandemen. Artinya include didalamnya kembali kepada GBHN ala orde baru. Sementara yang lain mengaspirasikan kembali dalam maknanya yang substansial yaitu sebuah GBHN yang more powerful dari pada RPJPN sekarang ini.Namun apapun aspirasinya, terdapat beberapa catatan yang perlu dicermati secara bersama manakala ingin mereformulasi GBHNagar benar-benar bergeraknya ke depan, bukan justru mundur ke belakang, yaitu bahwa situasi dan kondisi sosio politik nasional di era reformasi saat ini telah berbeda 180 derajat dengan di era orde baru.

Sebuah pertanyaan yang mungkin menarik untuk dicermati adalah kenapa atau bagaimanaGBHN di era Orde baru mampu bertahan selama 32 tahun dan menghasilkan capaiancapaian pembangunan yang senantiasa meningkat dari periode ke periode? Apakah karena GBHN itu berkedudukan sebagai TAP MPR semata-mata yang karenanya ia begitu powerful menjadi rujukan konsep pembangunan?

Pasca dihapuskannya GBHN sebagai pedoman pembangunan nasional, agenda rencana pembangunan nasional ditentukan lewat undangundang serta Rencana Pembangunan Jangka Menegah (RPJM) Nasional yang ditentukan dengan peraturan Presiden dan pelaksanaannya juga dilakukan oleh Presiden.Konsekuensinya, bila kinerja pemerintah tidak sesuai dari rencana 
pembangunan, maka tidak ada sanksi yuridis yang jelas. Karena ditentukan peraturan yang dihasilkan oleh kekuasaan Presiden itu sendiri.

2. Reformulasi

Pembangunan Nasional di Era

\section{Reformasi}

Untuk maksud di atas, banyak hal yang harus dikaji, baik secara yuridis, sosiologis dan metodologis. Yang harus pula diperhitungkan adalah perubahan paradigma berpikir yang ikut merubah arena, wajah dan struktur politik. Dalam era Reformasi, demokrasi mulai terkondisi di berbagai lini kehidupan,sekalipun demokrasi yang dilahirkan di Indonesia abortus sehingga menjadi industri politik. Semua identitas yang muncul dan berkembang di dalam masyarakat mendapat ruang. Semua kelompok dari berbagai kalangan mendapat tempat untuk menyalurkan aspirasi dan ikut berpartisipasi dalam pemerintahan. Tidak ada diskriminasi terhadap kelompok tertentu, hak untuk berperan serta dalam pemerintahan atau kegiatan politik terbuka selebar-lebarnya bagi semua kelompok yang ada.

Dapat dianalisis bahwa tidak adanya GBHN merupakan akibat langsung dari hilangnya eksistensi lembaga tertinggi negara atau MPR. Oleh karena itu tidak akan ada lagi PROPENAS yang merupakan penjabaran dari GBHN, dan tidak akan ada lagi PROPEDA yang merupakan penjabaran dari PROPENAS. Hilangnya koridor perencanaan makro yang selama ini, telah menjadi arahan dan panduan bagi pelaksanaan perencanaan pembangunan bisa menimbulkan kesemrawutan yang semakin parah. Perubahan ini bisa menimbulkan kebingungan terutama ditingkat lokal dan di level operasional. Beberapa pihak tetap merasa optimis karena pada dasarnya GBHN tidak hilang namun akan digantikan oleh program-program pembangunan yang telah disampaikan oleh Presiden terpilih pada saat Pemilu. Namun tentunya masih harus dikaji kembali apakah keberadaan program kerja Presiden tersebut dapat menggantikan peranan GBHN atau bahkan menjadi lebih efektif.

Mencermati keberadaan pedoman perencanaan pembangunan dari perspektif situasi dan kondisi saat ini memang terasa dilematis. Harus diakui bahwa memang ada masalah. RPJPN yang kita miliki saat ini potensial bermasalah dari sisi statusnya sebagai Undang-Undang karena terasa kurang 
ISSN 2528-360X e-ISSN 2621-6159

powerful dan masa waktunya yang berjangka 20 tahun karena belum tentu kompatibel dengan situasi dan kondisi demokrasi yang telah terbangun saat ini. Dan seandainya ingin kembali kepada GBHN, maka GBHN ala orde baruharus dihilangkan dan disesuaikan dengan situasi dan kondisi sosio politik yang memang sudah berbeda saat ini. Lalu bagaimana solusinya? Dalam hal ini ada duaalternatif yang menurut penulis layak dipertimbangkan adalah:

a) Dengan mengembalikan kewenangan MPR untuk menyusun dan menetapkan GBHN lewat Perubahan ke-V UUD 1945. Karena Presiden hanya menjalankan Programprogram yang telah ada dalam GBHN yang telah ditentukan tiap 5 tahun dan tidak perlu membuat program baru lagi yang bisa saja tidak efektif dan tidak menguntungkan rakyat. Selain itu GBHN dirancang, dirumuskan, dan ditetapkan oleh MPR. Hal ini memilki keunggulan dibanding ketetapan dalam bentuk UndangUndang karena mengubah Ketetapan MPR memerlukan konsensus politik yang lebih tinggi daripada undang-undang
Volume 1 No. 1 Desember 2016 sehingga lebih menjamin konsistensi dan kesinambungan pembangunan siapa pun presidennya nanti. Konsisten berarti diikuti dan ditaati oleh seluruh penyelenggara negara secara horisontal dan vertikal dari pusat ke daerah. Berkelanjutan artinya diikuti dan ditaati oleh setiap rezim meskipun berganti-ganti setiap lima tahun. Oleh karena itu RPJMD juga harus disesuaikan dengan RPJMP dengan tetap mengakomidir tuntutan daerah dalam sistem pembangunan.

b) Jika tetap menggunakan RPJPN, maka Statusnya perlu dirubah dari Undang-Undang menjadi keputusan MPR agar mendapat legitimasi yang kuat. Sehingga tidak diperlukan lagi amandemen terhadap UUD 45 terkait dengan wacana memasukan kembali GBHN dalam kewenangan MPR. RPJP yang ada saat ini sebenarnya juga sudah cukup detail dan komprehensif, 
ISSN 2528-360X e-ISSN 2621-6159

C. PENUTUP

GBHN di masa lalu merupakan bagian dari produk politik hukum. Namun secara politis difungsikan sebagai sarana kontrol sosial pemerintah. Ke depan, jika ingin diterapkan kembali, GBHN diarahkan tidak sekedar menunjang pembangunan nasional namun juga perbaikan kehidupan berbangsa. Kendati dalam pelaksanaannya berbenturan dengan perilaku politik penyelenggara negara.Namun yang mendesak, perlu perbaikan praktik politik sehari-hari agar muatan moral yang terkandung dalam RPJPN atau GBHN atau produk lainnya tidak dimain-mainkan melalui tafsir politis. Reformulasi GBHN memiliki peranan sebagai instrument penyelenggaraan pemerintahan. Model GBHN lebih dimaksudkan untuk mengambil inspirasi dalam rangka mengoptimalkan tata pemerintahan Indonesia yang dapat mensinergikan pemerintah nasional dan lokal yang memiliki otonomi luas. Jika GBHN kembali dihidupkan melalui amandemen UUD 1945 akan mengundang konsekuensi mengenai mekanisme pemilihan presiden secara langsung karena menghidupkan kembali GBHN maka, bisa saja MPR kembali menjadi lembaga tertinggi negara dan mempunyai kewajiban untuk memilih kembali presiden disamping membuat dan menetapkan GBHN.

\section{DAFTAR PUSTAKA}

Moeljarto Tjokrowinoto. 1993. Politik Pembangunan, Sebuah Konsep, Arah dan Strategi, Tiara WacanaCet-2. Yogyakarta.

Riyadi \& Supriadi B., Deddy, 2005.Perencanaan Pembangunan Daerah. Strategi Menggali Potensi dalam Mewujudkan Otonomi Daerah. Gramedia Pustaka Utama. Cet-3. Jakarta.

Sjaifudian, H. 2000. Desentralisasi dan Prospek Partisipasi Warga dalam Pengambilan Keputusan Publik. Jurnal Analisis Sosial (Social Analysis Journal)Vol. 5. 